\title{
Analyzing Demand Drivers of Enterprise Informatization Based on System Dynamics Method
}

\author{
Yijun Huang, Weiguo Wang, Jun Wu, Xue Yan, Rong Liu, Lei Dai, Tian Guo and \\ Honglin Song \\ School of Economics and Management, Beijing University of Posts and Telecommunications, \\ Beijing 100876, P.R. China \\ hyijun@vip.sina.com Wang@bj1860.net junwu@bupt.edu.cn yanxuebaby@gmail.com \\ liurong@buptinfo.com d10129kathy@sina.com guotian1213@sina ssppwudi@126.com
}

\begin{abstract}
With the popularization of networks, digitalization and automation, demand for enterprise informatization becomes more urgent. There are many factors leading to the demand for EIS. Some of the factors are from enterprise development, while others are from policy driven. In this paper, we present a relationship model by using system dynamics method to characterize the causeresult (C-R) of demand drivers of enterprise informatization. Based on the empirical studies, we reveal how the factors affect the demand for enterprise informatization, which form a cluster of causation to be used as the cause variables in our model. This procedure is to settle on the interim variables and result variables, which formed systematic dynamics C-R charts. Questionnaires and interviews from dozens of enterprises, Delphi Expert Decision method are made and analyzed, which verified the relationship between variables. The results presented in this paper provide good insights for the enterprise managers' optimal decisions.
\end{abstract}

Keywords: Information system, Demand driven, System dynamic, EIS, Enterprise informatization

\section{INTRODUCTION}

Infomatization was a hot issue in China's development. With the network globalization, the widespread digitalization and automation, infomatization attracted much attention than ever before not only by Chinese enterprises but also by Chinese government. In this environment, different enterprises exhibited different intensity of demand in constructing the infomatization. The difference resulted in different attifude towards infomatization, its practical effect and the force they popularizing it. It was known as "the infomatization gap". What was the cause of it? This paper aimed to find the key reason of this interesting phenomenon.

There were a lot of researches in this area. Eric Shih's [1] research indicated that in different countries, there were different factors. Xiaopeng An [2] presented that the developed countries, for example, America and Britain, were both featured by the fact that their infomatization were activated by the highly advanced market system. The

Please use the following format when citing this chapter:

Huang, Y., Wang, W., Wu, J., Yan, X., Liu, R., Dai, L., Guo, T., Song, H., 2007, in IFIP International Federation for Information Processing, Volume 255, Research and Practical Issues of Enterprise Information Systems II Volume 2, eds. L. Xu, Tjoa A., Chaudhry S. (Boston: Springer), pp. 1227-1237. 

Honglin Song

government didn't intervene but only gave a macroscopical guidance. As a socialism developing country, China had better to take the difference action from the developed countries. For example, in China and other developing countries, with the macrocontrol as a leading position and the market system not fully developed, the interest rate could affect the enterprises' process of informatization little. Thereby, it was more important to disclose the nature of the developing countries' process of infomatization by looking into the enterprises' infomatization demand based on Chinese characteristics.

The research in this paper was based on the theory of System Dynamics and its model constructing method. With the previous research and the market questionnaires from 32 enterprises by visiting and 17 questionnaires by experts in the country, we found the main factors that affect the intensity of the enterprises' demand of infomatization. By that way, the overall collection of influence factors was settled.

\section{LITERATURE REVIEW}

The research objective of this paper was the demand intensity of Chinese enterprise informatization. The research aimed at finding out the influence factors affecting this variable and to what degree they affected it. One of the basic tasks of this paper is to sum up the influence factors of the enterprise informatization from the literature.

\subsection{Analyzing the Influence Factors of the Enterprise Informatization in the Social Perspective}

According to Eric Shih [1], as the developed countries had well-developed market economy system, the influence factors of the enterprise informatization were interest rate, credit system, etc; while in the developing countries, the major influence factors were government, foreign trade, knowledge level, etc. Xiaopeng An $[6,2,7]$ indicated that the process of enterprise informatization in China had a different prominent feature that the government possessed great regulating and leading power. The governments at all levels attached a great importance to the enterprise informatization and helped to promote its development; the government's credit standing and resources were fully used. For example, the government investment could attract the investment from the enterprises and the government control could improve summarization and demonstration of the typical experiences, etc. Yang Oufeng [8], Lijuan Liu [9] and Changbo Qiu [10] also pointed out that.

1 System Dynamics(SD), which started in 1956, was created by the system dynamics group leading by Pro. Forrester in Massachusetts Institute of Technology. It is called Industry Dynamics [4]at the beginning. SD has absorbed the essence of the Cybernetics theory and the Information Theory. It mainly looked into the system's inner structure, the flow of the matter, the flow of the information and their feedback structure, and constructed the system dynamic model and explained the system dynamic behavior based on that. The basic conception of SD referred in this paper is Cause-Result feedback: if an event $A$ (cause) cause an event B (result), $A$ and B forms a C-R relation. VENSIM PLE5.6 as a Simulation language is used in this paper. 
So it was of great difference between the situation in China and those in the developed countries. In November 3rd, 2005, the Chinese government for the first time clarified the informatization responsibility of the state, the industry and the enterprise in the form of The State Informatization Development Strategy [11]. Therefore, the government was a more direct and special driving factor of the informatization demand. It usually exerted its influence by cutting in through the top management of the industries and the enterprises and then penetrating by the government behavior. And this point had been confirmed again in the Enterprise Informatization Summit Forum [12]: the government's impetus and support was the key factor for the enterprise informatization.

As a conclusion, in the social perspective, the influence factors of the enterprise informatization included two categories: first, the impetus of the government, including polices and requirements, funding support; second, the macro environment of the industry, mainly referring to the impetus from the informatization of the supply chain.

\subsection{Analyzing the Influence Factors of the Enterprise Informatization in the Enterprise Perspective}

Direct research on the influence factors of enterprise informatization. Leoni Warne, Dennis Hart [13] concluded five main influence factors of the informatization in the developed countries through 290 expert questionnaires. They were: the alignment with business need, the top management support, the user involvement, the effective project management, the use of a system development methodology. Xie Kang [14] studied the Chinese enterprise and got a conclusion that it was the market competition and the phase of the enterprise development that affected the demand intensity and the structure transformation of the enterprise informatization. Hee-Woong Kim [15] pointed out that the enterprise informatization was greatly influenced by the top management recognition, the employee's average IT skill, the system integrity and the system functions. Yongyi Shou, Ying Ying [17] studied the enterprises in Hangzhou area in Zhejiang province of China and elicited these influence factors of a successful enterprise informatization: the participation of the staff, the management and the technology authority of the IT group, business process re-engineering, the reasonable expectation for the technology, etc. Feng Ouyang [8] thought the enterprise informatization was affected by the interior factors including the phase of the enterprise development, the information technology investment, the duty transformation of the entrepreneurs, the qualifications of the managing personnel and the employee's information consciousness, etc; and the exterior factors including the government, the market environment and the support of the information facilitators. Changbo Qiu [10] figured out the key influence factors through the integration of canonical correlations analysis and the quantitative research: the top management recognition, the IT skill of the staff, the investment on enterprise informatization, the state of the management system, the cooperation between different departments. According to Eric Shih and his group [7], the employee's average IT skill, consultant expert's opinion, their management level and their phase of development were the 
main influence factors. Furthermore, in the enterprise informatization summit forum, many enterprise top managers reached a consensus that the funding factor and human resource factor were very important factors.

Analyzing the influence factors in the perspective of enterprise strategy. Qian Weimin [16] put forward the theory in the perspective of the enterprise strategic planning that the strategic factors of the enterprise informatization included the IT implementation planning, CIO, devotion of the full staff, top manager project, IT program management, reasonable aim, system technology, etc.

Analyzing the influence factors in the perspective of the enterprise informatization and success chance of information system. Mohammad Jafar Tarokh and Javad Soroor [18] carried out a special research on the reason for the failure of developing the management system of the supply chain and arrived at a conclusion that the enterprise management level, the consultant's qualification, the input-output benefit and the too complicated system were the reasons. Huaming Di [19] argued that the qualifications of the informatization personnel had a direct influence on the result of informatization. The website of IT procurement for Medium and small enterprise [21] and Xuemei Guo [22] carried out a territorial research on the informatization of inner Mongolia medium and small enterprises and reached a conclusion that the top management support, funding support had become the leading factors in building the enterprise informatization; the informatization criterion, the participation of full staff, the support of the suppliers of infomatization products also greatly affected the enterprise informatization process.

To sum up, in the enterprise perspective, the influence factors of the enterprise informatization included: top management recognition and support, the employee's average IT skill, important employee's consciousness and support, the endeavor of IT staff, informatization planning, funding guarantee of informatization, the criterion level of operational processing, consultant expert's opinions, management level, the enterprise development phase, market competition.

\subsection{The Research Methodology for the Influence Factors of Enterprise Informatization}

At present, there were several research methodologies of the influence factors of enterprise informatization: structural equation Modeling, meta-analysis, Model performance and output. The data came from the questionnaires and statistics, like the literature $[1,17,18,13,15]$. Thomos Puschmann, Rainer Alt [23], Jake M. Kosior, Doug Strong [24] focused their research on confirming the key factors and how powerful their influence were. And their research provided a powerful foundation for the later study of this paper. Other scholars' research mostly reflected the judgments of influence factors in the developing countries, especially in China.

This paper was mainly featured as qualitative analysis, using Empirical investigation in the form of questionnaire as its minor method. Differed from the previous research, this paper introduced system dynamics means, which introduces systematic and C-R analysis. It was suitable for the dynamic and complex social 
system. It was a systematic comprehensive analyzing method and an integration of qualitative analysis and quantitative analysis.

\section{DETERMINATION OF THE FACTORS OF DEMAND INTENSITY OF ENTERPRISE INFORMATIZATION}

\subsection{Research Method}

The main idea of this part was the systematic thought by using SD method.

First of all, according to the collation and summarization of literature, we preliminarily extracted the influence factors of enterprise informatization. Those factors were important sources of influence factors of demand intensity. Then in order to confirm that those factors could really affect the demand of enterprise informatization and find out the other indispensable factors that the literature didn't mention, we carried out an investigation by visiting enterprises. By that way, the overall collection of influence factors was settled. And finally, the influence relations between those factors in the collection were evaluated through the expert questionnaires. So the collection of the factors was optimized once again and laid a foundation for the later $\mathrm{C}-\mathrm{R}$ diagram.

The enterprise visiting and the expert evaluation were both composed of three progressive levels of questions. The first level was the validation of the qualitative relation: Did the factors summarized from the qualitative collation of literature could affect the demand intensity of enterprises informatization? Was there any other factor that had been neglected? The second level: if a certain influence relationship did exist, then what was the cause variable, and what was the result variable? Or were they reciprocal causation? Due to the reciprocal causation structure between the variables, there formed a complicated dynamic feedback system. The third level: to what degree the cause variables could affect the result variables?

\subsection{Preliminary Selection and Validation and Supplement of Factors}

According to literature review, we concluded 14 factors. Since those factors were not directly affecting the demand intensity of informatization, in order to improve the reliability, we conducted two investigations. The first one was an interview. Within a month, we visited 32 enterprises in China, which differed in their industries, size and locating areas. The major forms were interviews inside the enterprise and questionnaires. Then we got the result on the influence factors of demand intensity of enterprise informatization and their importance as following:

(1) "Top management recognition and commitment" was the most important factors $(88 \%$ of the enterprises chose "very important"). Through the relativity 
1232 Yijun Huang and Weiguo Wang, Jun Wu, Xue Yan, Rong Liu, Lei Dai,Tian Guo and Honglin Song

analysis, it was also proved that this result had no relation with the enterprises' character, scale, and present level of informatization, etc.

(2) There came up four factors that were indispensable for enterprises but the literature didn't mention: practical informatization experience of their own or that of the other enterprises, informatization level of the industries, the informatization level of the enterprise compared with that of the industry it was in, their own demand of business development.

(3) There were four factors that didn't mention in the literature but were confirmed in the enterprise investigation: informatization planning, criterion level of operational processing, the enterprise management level and the supply chain factor.

Therefore, this paper used Delphi Expert Decision Method to determine that in what aspects the factors from the literature and enterprise investigation would affect the demand of informatization. The consensus opinion of the experts was that the 8 factors mentioned in (2), (3), exerted important influence in different aspects. Moreover, they brought up other two factors: the legal system of imformatization and the rivals' investment level of imformatization.

To sum up, we presented a list of 20 influence factors shown in Table 1.

Table 1. The Influence Factors of Enterprise's Demand Intensity of Informatization

\begin{tabular}{|l|l|l|l|l|}
\hline NO. & \multicolumn{1}{|c|}{ key factors } & $\begin{array}{l}\text { from } \\
\text { literature }\end{array}$ & $\begin{array}{l}\text { from } \\
\text { enterprise } \\
\text { investigation }\end{array}$ & $\begin{array}{l}\text { from } \\
\text { expert } \\
\text { evaluation }\end{array}$ \\
\hline 1 & top management commitment and support & $*$ & $*$ & $*$ \\
\hline 2 & the endeavor of IT group & $*$ & $*$ & $*$ \\
\hline 3 & important employee's support and participation & $*$ & $*$ & $*$ \\
\hline 4 & enterprise staff's average IT skill & $*$ & $*$ & $*$ \\
\hline 6 & the enterprise development phase & $*$ & $*$ & $*$ \\
\hline 7 & market competition[EX] & $*$ & $*$ & $*$ \\
\hline 8 & $\begin{array}{l}\text { the government impetus(requirements and policy } \\
\text { thvironment) [EX] }\end{array}$ & $*$ & $*$ & $*$ \\
\hline 9 & $\begin{array}{l}\text { the enterprise development funds were enough } \\
\text { comparatively }\end{array}$ & $*$ & $*$ & $*$ \\
\hline 10 & $\begin{array}{l}\text { informatization expert's consultation } \\
\text { suggestion[EX] }\end{array}$ & $*$ & $*$ & $*$ \\
\hline 11 & the management level of enterprise & $*$ & & $*$ \\
\hline 12 & the criterion of operational processing & $*$ & & $*$ \\
\hline 13 & informatization planning & $*$ & & $*$ \\
\hline 14 & global supply chain factor[EX] & $*$ & & $*$ \\
\hline 15 & $\begin{array}{l}\text { the enterprise or other's practical experience of } \\
\text { informatization[EX] }\end{array}$ & & $*$ & $*$ \\
\hline 16 & $\begin{array}{l}\text { the demand deriving from enterprise business } \\
\text { development }\end{array}$ & & $*$ & $*$ \\
\hline 17 & the level of industry's IS[EX] & & $*$ & $*$ \\
\hline 18 & the IS level of enterprise in the industry & & $*$ \\
\hline 19 & legal system of IS[EX] & & \\
\hline 20 & $\begin{array}{l}\text { level of competitor's informatization } \\
\text { investment[EX] }\end{array}$ & & $*$ \\
\hline
\end{tabular}

Ps: $[\mathrm{EX}]$ represent exterior variables (detail in 4.1 ) 


\section{C-R DIAGRAM OF DEMAND INTENSITY OF ENTERPRISE INFORMATIZATION BASED ON SYSTEM DYNAMICS}

\subsection{Outline of C-R Relation}

From the system perspective, we first determined the environment factors and interior factors of the system and thereby settled the boundary. On this basis we subdivided system and got a subsystem structure. And then based on conclusion of expert evaluation and enterprise visiting, we determined what Exogenous Variables and Endogenous Variables could affect the factor variables in every subsystem, that was, the detailed $\mathrm{C}-\mathrm{R}$ relation. And finally the complete $\mathrm{C}-\mathrm{R}$ diagram came into being.

The demand intensity of enterprise informatization we studied in this paper was based on enterprises. The factors and variables related to the enterprise interior operation and under the enterprise's control were interior factors and variables of the system. The factors from the outside of the enterprises, affecting their interior operation and beyond their control were exterior factors. In system dynamics (Jia Renan, Ding Ronghua, [4]), interior variables were called Endogenous Variables; exterior variables were called Exogenous Variables. The collection of Exogenous Variables forms system environment. Therefore, the enterprise boundary, in this paper, was the system boundary.

Among the 20 influence factors in Table 1, the ones marked with [EX] were Exogenous Variables and there were 9 of them; the others were endogenous variables.

\subsection{Complete System C-R Diagram}

The system of demand intensity of enterprise informatization was composed of five aspects of factors: top management personnel, interior demand, capital factors, human resource factors and exterior demand. Those factors and the whole demand intensity formed a reciprocal causation. As the demand intensity of informatization and the adequate funds formed a negative correlation, except for the capital factor, other factors formed a circle of positive feedback. According to the 7 base models Peter Senge [25] defined, this was a growth-to-limit base model (See Fig. 1). 
1234 Yijun Huang and Weiguo Wang, Jun Wu, Xue Yan, Rong Liu, Lei Dai,Tian Guo and Honglin Song

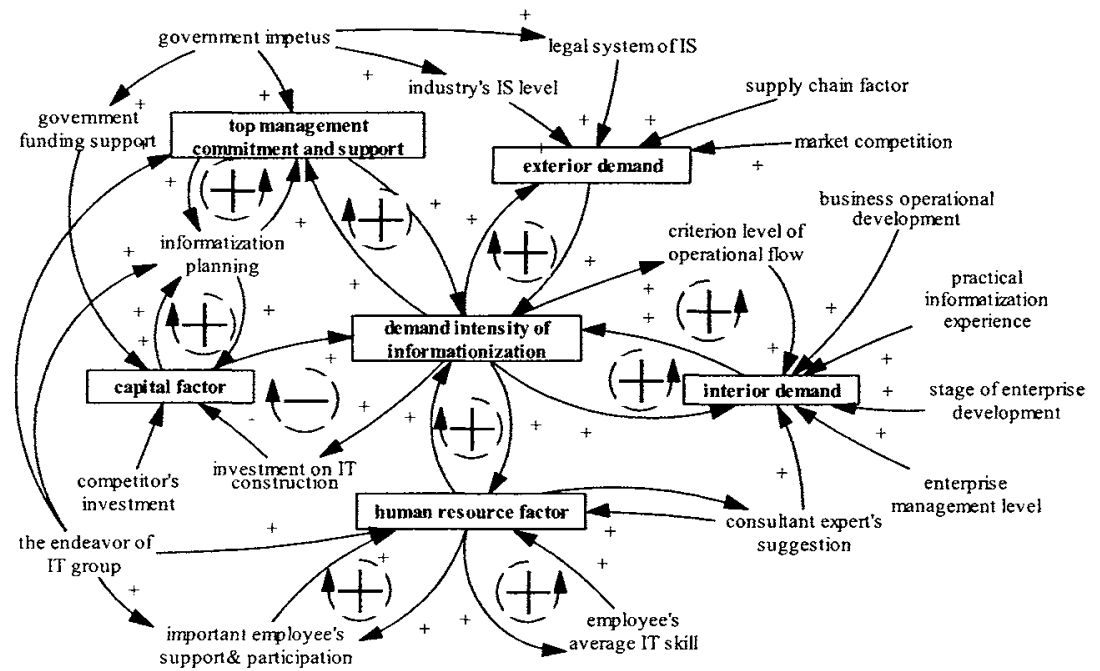

Figure 1. Complete C-R Diagram of the Demand Intensity of Infomationization

(Ps: in the C-R diagram, the arrows pointing from Cause to Result represented a certain result's cause or influence factor; the " + , -"signed on the arrows represented the positive and negative correlations; arrows without a sign indicated that the correlation was uncertain.).

There formed a complicated C-R relation between the 20 influence factors (cause variables) and the demand intensity of informatization (result variables). For example, when top management recognition and support improved, it would accelerate the informatization planning and improve the intensity of informatization. In the same way the acceleration and improvement of the later two would promote the former's development. In other words, every result variables should affect the cause variables, namely, the output affected the input. It was a feedback relation. Hereby, one of the important reasons to carry out the expert evaluation was to find the interaction relation between the factors. Part of the C-R relation has been mentioned in the previous analysis and summarization. The latest $C-R$ relation among the factors was in the complete C-R diagram (See Fig. 1).

\section{OTHER RESULTS FROM THE RESEARCH}

We also got some other results which had not been included in the C-R diagram but still very valuable.

(1) Chinese enterprises had a strong consciousness of informatization. But their interior development and the market environment hadn't reached the required mature state. In the enterprise investigation, we also asked them to evaluate their present state of the important factors they had raised. Apparently, those top managers highly valued and supported the informatization. That was due to the fact that the government began to accelerate the process of informatization since 2006. From the facts that the funds was relatively adequate and that the endeavor of IT departments 
was basically approved, we could see that enterprises were really attaching great importance to informatization at present. And now there were mainly two aspects that greatly behind the enterprise's expectation: firstly, the enterprises hadn't reached the stage that informatization work could be fully carried out, that was, the concept of informatization was much forward than the actual state of the enterprises; secondly, there was not enough impetus from the market competition they were facing and their interior demand of business development to drive their demand of informatization. According to the investigation, $84 \%$ of the enterprises had OA system and financial management system, $50 \%$ of them have CRM system, but only $16 \%$ of them had systems related with production and management like logistical distribution and marketing.

(2) Chinese enterprise informatization was in the growth stage. It was subject to more exterior factors' influence. Among the investigated enterprises, there were only $32 \%$ of them made informatiztion plans, which meant that the informatization demand hadn't become domination. This apparently conflicted with the reality that the top managers paid much attention to it. In fact, Chinese enterprises suffered more exterior influence than the enterprises in the developed countries. For example, because the social credit system was incomplete, it raised the risk for the enterprises to use the informatization as their commercial support; because the information security technology was immature, it reduced the chance for the enterprises to select informatization, etc.

\section{CONCLUSIONS}

This paper exhibited the overview of the demand intensity of enterprise informatization in the form of C-R diagram of system dynamics. It provided a reference basis for the research in factor judgment and selection, relativity analysis and simulation model construction. From the above analysis, we had obtained some interesting results: (1) The generation and intensity of enterprise informatization demand were affected by many factors. In the developing countries like China, the exterior factors (Exogenous variables) exerted a much strong influence, mainly including the impetus of the government, market competition, informatization level of the industry, supply chain factors. And in the interior factors (endogenous variables), the factors relating to the human resource were the most important factors, including the top management commitment and support, the employee's average IT skill, the endeavor of the IT group and other important employee's support and participation. Moreover, informatization planning, available funds for the informatization, business development, the enterprise management level and the criterion level of operational processing were the important endogenous variables affecting the demand. This paper settled 9 exogenous variables and 11 endogenous variables through literature review, enterprise investigation and expert questionnaire. (2) In constructing infomatization, more attention should be paid to the enterprise's top managers. When enterprises were not in suitable infomatization condition, it was suggested not to construct or promote products; when certain condition was provided, but not mature enough, it was suggested to develop selective construction or promoting activities; when condition 
1236 Yijun Huang and Weiguo Wang, Jun Wu, Xue Yan, Rong Liu, Lei Dai,Tian Guo and Honglin Song

was mature enough, it was suggested to solidify infomatization into their management and make infomatization as one of the competitive abilities in the Information Age.

\section{REFERENCES}

1. E. Shih, L.K. Kraemer, and J. Dedrick, Determinants of Country-Level Investment in Information Technology, Management Science. Volume 53, Number 3, pp.521-528, (2007).

2. X. An, The process, Features and Enlightenment of Foreign enterprises in informatization (2002). http://www.niec.org.cn

3. L. Yuan and S. Jiang, System Dynamics-the Theory and Methods of Social System Simulation (The Zhejiang Press: pp.10, 1988).

4. R. Jia and R. Ding, System Dynamics-Analysis of Feedback Dynamic Complexity (The Higher Education Press: 2002).

5. J.W. Forrester, Industrial Dynamics (The M.I.T. Press. And John Wiley \& Sons Inc: New York \& London: 1961).

6. X. An, The Informatization and the Spanning Developing in China, China Computer Paper (April 24, 2002).

7. X. An and H. Wang. The Review and Prospect about Informatization in China (May 15, 2003). http://www.cctd.com.cn

8. F. Ouyang and Y. Li. Understanding and Grasping the Key factors of the Enterprise Informatization, Developing in a Scientific Way, The Progress and Countermeasure of Technology. Number 11, pp.167-169, (2005).

9. L. Liu, The informatization of medium-and-small-sized Enterprises: the Cheese seen well but Unpalatable, The Business Watch Magazine (June 7, 2006).

http://www.businesswatch.com.cn

10. C. Qiu, M. Shi, and J. Zhang. The Canonical Correlation Analysis of Key Influencing Factors of the Enterprise Informatization, Jilin University Journal (Information Science). Volume 24, Number 5, (2006).

11. National Informatization Development Strategy, CPC Central Committee General Office and the Office of the State Council. 2006-2020 (2006). http://news.xinhuanet.com

12. China medium-and-small-sized Enterprises Informatization Exchange Spring Peak Dialogue, China Electronic Information Industry Development Institute. http://info.cecceda.org.cn (Accessed April 11, 2007)

13. L. Warne and D. Hart. The Impact of Organizational Politics on Information Systems Project Failure - A Case Study. System Sciences, in Proc. of the Twenty-Ninth Hawaii International Conference on, Volume 4 (1996), pp.191-201.

14. K. Xie, The Information Demand of Chinese Enterprises and the Modes of Investment on Informatization, The Management World. Number 3, pp.96-103, (2000).

15. H.W. Kim, A Process Model for Successful CRM System Development, Software, IEEE. Volume 21, Number 4, pp.22-28, (2004).

16. W.Qian, The Ten Elements of the Enterprise Informatization Strategy, The Chinese Paper Industry. Number 1, pp.77-80, (2004).

17. Y. Shou and Y. Ying, Critical Failure Factors of Information System Projects in Chinese Enterprises, in Services Systems and Services Management, 2005 Proceedings of ICSSSM 05. 2005 International Conference on Volume 2 (2005), pp.823-827.

18. M.J. Tarokh and J. Soroor, Supply Chain Management Information Systems Critical 
Analyzing Demand Drivers of Enterprise Informatization Based on System Dynamics Method 1237

Failure Factors, in Proc. of Service Operations and Logistics and Informatics, 2006, SOLI '06. IEEE International Conference on June 2006 (2006), pp.425-431.

19. H. Zhai, The Structure of Skill-People in Enterprise Informatization and Analysis of Job Responsibility, The Modernization of Marketplace. Volume 457, pp.217-218, (2006).

20. $\mathrm{X}$. Hu and X. Li, The Model Building and Analysis of Informatization Strategy of Small \& Medium Sized Enterprises, Fujian Computer. Number 9, pp.46-49, (2006).

21. The Editor of CBI SMB, SME information Inner Mongolia regional status report of investigation. http://www.cbinews.com (Accessed April 10, 2007).

22. X. Gou, The Long March of SME informatization-chapter in Inner Mongolia http://www.cbinews.com (Accessed April 10, 2007).

23. T. Puschmann and R. Alt, Enterprise application integration systems and architecture-the case of Robert Bosch Group, The Journal of Enterprise Information Management. Volume17, Number 2, pp.105-116, (2004).

24. J.M. Kosior and D. Strong, Supply/demand chain modeling utilizing logistical-based costing, Journal of Enterprise Information Management. Volume 19, Number 3, pp.346$360,(2006)$.

25. P.M. Senge, The Fifth Discipline: The Art and Practice of the Learning Organization (New York: Doubleday/Currency, August 1990). 